\title{
ANTIMICROBIAL SUSCEPTIBILITY PATTERN OF STAPHYLOCOCCUS AUREUS STRAINS IN ISLAMABAD, PAKISTAN
}

\author{
Ambreen Gul, Yasir Rasheed, Kaleem Imdad, Raheela Yasmin, Aneela Jamil, Ummara Aslam
}

\begin{abstract}
Objective: To investigate the prevalence of S. aureus in hospitalized patients of Islamabad.

Study Design: Cross-sectional study.

Study Duration: Pakistan Institute of Medical Science, Applied Microbiology and Biotechnology Lab, COMSATS Institute of Information Technology, Islamabad, from Sep 2017 to Sep 2018.

Methodology: A total of 500 samples were collected. The isolates were divided into four study groups according to their source of origin i.e. group 1 (dermal group), group 2 (nasal group), group 3 (blood group) and group 4 (urine group). Gram staining, catalase test and DNA se media analysis were done for validation of $S$. aureus. Disc diffusion test (for antibiotic susceptibility), Oxacillin disc test (to differentiate between methicillin-resistant Staphylococcus aureus and methicillin-susceptible staphylococcus aureus) and minimal inhibitory concentration (for susceptibility to vancomycin), were performed.

Results: Degree of the prevalence of staphylococcus aureus was $21 \%, 17 \%, 9 \%$ and $8 \%$ in group 1, 2, 3 \& 4 respectively. The overall prevalence of staphylococcus aureus was $19.5 \%$ in all isolates. The disc diffusion test showed the descending resistance pattern of isolates i.e. 100, 94, 94, 76, 58, 55, 47, 43, 40 and 37\% for penicillin, ciprofloxacin, Kanamycin, erythromycin, tetracycline, oxazolidinone, sulfamethoxazole, doxycycline, clindamycin, and cipoxin respectively. Minimal inhibitory concentration found only one sample resistant at $2 \mathrm{ug} / 1$ concentration of Vancomycin. Moreover, Oxacillin disc test showed 52\% methicillin-susceptible Staphylococcus aureus while $48.2 \%$ methicillin-resistant staphylococcus aureus among all isolates.

Conclusion: There is an increase in the frequency of methicillin-resistant staphylococcus aureus. Single vancomycin resistant staphylococcus aureus strain was also isolated.
\end{abstract}

Keywords: Antimicrobial, Islamabad, Pakistan, Staphylococcus aureus, Susceptibility.

This is an Open Access article distributed under the terms of the Creative Commons Attribution License (https://creativecommons.org/licenses/by-nc/4.0/), which permits unrestricted use, distribution, and reproduction in any medium, provided the original work is properly cited.

\section{INTRODUCTION}

Staphylococcus aureus (S. aureus) is the leading cause of hospital and community-acquired infections with severe consequences. Blood stream, skin, soft tissues and lower respiratory tracts are targeted in Nosocomial S. aureus infections. Major deep-rooted infections, such as endocarditis and osteomyelitis, toxinmediated diseases, such as toxic shock syndrome, scalded skin syndrome and staphylococcal foodborne diseases may also be the result of $S$. aureus. The weak immune system, numerous catheter insertions and injections are responsible for infections in hospitalized patients ${ }^{1-3}$. $S$. aureus is provided with diverse virulence factors, which include both structural and secreted products which contribute to the pathogenesis of infection ${ }^{4}$.

In the last decade, resistance and reduced susceptibility to antibiotic agents has become a major medical concern $^{5}$. The incidence of bacterial infection was reduced with penicillin discovery in 1940. But then penicillin $\beta$-lactam core ring was destroyed by $\beta$-lactamase

Correspondence: Dr Ambreen Gul, Department of Biochemistry, HITEC-Institute of Medical Scences, Taxila Pakistan

Received: 08 Oct 2020; revised received: 14 Feb 2021; accepted: 24 Feb 2021 which Staphylococcus aureus started producing. $\beta$ lactamase resistant methicillin was developed which was effective against Staphylococcus aureus until the first strain of methicillin-resistant S. aureus (MRSA) were separated in 19617.

Vancomycin was considered the most effective medicine for MRSA infections. In Japan, the vancomycin-resistant strain was detected in 1996. In 1958, vancomycin was introduced for medical practice, for treating gram-positive bacterial infection ${ }^{8}$. A specific group of $S$. aureus, known as hetero-VRSA, rapidly develop VRSA (vancomycin-resistant Staphylococcus aureus strain), when exposed to vancomycin. Existence of heteroVRSA indicates an adverse decrease in the effectiveness of vancomycin in clinical biology. Excess amounts of peptidoglycan cause an increase in the size of the cell wall as the result of which resistance developed against the antibiotic. This is a simple mechanism for all VRSA identified around the globe so far ${ }^{9}$.

In Pakistan and particularly Islamabad region, only limited data is available on the susceptibility of MRSA to antibiotics predominantly vancomycin. The current study reveals the prevalence of multidrugresistant MRSA strains and examines their antibiotic 
sensitivity pattern in a tertiary care hospital of Islamabad.

\section{METHODOLOGY}

This cross-sectional study was conducted at the Pakistan Institute of Medical Science Islamabad, from September 2017 to September 2018. Different type of samples including blood, urine, wound secretions and nasal secretions were collected from the patients in Pakistan Institute of Medical Science (PIMS) Islamabad. The samples were taken through gel swab or in blood vales and transported to the Applied Microbiology and Biotechnology Lab, COMSATS Institute of Information Technology, Islamabad in 12-24 hrs. Samples were cultured on the same day. Patients with any co-morbidity were excluded.Written consent was taken. Ethics approval for the study was obtained from the ethics review board committee of the COMSATS Institute of Information Technology, Islamabad (CIIT/ Bio/ERB/17/25).

All the blood samples were cultured in blood culture bottles containing broth (Thermo USA). The culturing bottles were incubated in Automated Blood Culture System (ABCS). The presence of bacteria was indicted by machine and bacteria-containing tubes were further cultured on McConkey agar. The samples of nasal secretions and pus samples were cultured on chocolate agar or McConkey agar and incubated at 37C for 18 to $24 \mathrm{hrs}$. Urine samples were cultured on CLRD media and incubated at $37^{\circ} \mathrm{C}$ for $24 \mathrm{hrs}$.

The presence of $S$. aureus was checked through colonial morphology as they give small grey-white colony of $1-2 \mathrm{~cm}$ on agar. Presence of staphylococcus aureus was further confirmed through gram staining, catalase and DNAse test as they are positive for all of these tests.

After confirmation staphylococcus aureus colonies were purified on nutrient agar for further study. A single colony of $S$. aureus was picked from nutrient agar and inoculated in test tubes having LB broth and incubated on shaking incubator at $370 \mathrm{C}$ for $24 \mathrm{hrs}$. Glycerol stocks were produced by homogenizing 50\% glycerol solution and bacterial culture (freshly grown) in 1:1 ratio. The bacterial glycerol stocks were preserved at $-200 \mathrm{C}$.

The susceptibility of all positive cultures which yields S. aureus were checked on Mueller-Hinton agar by using disc diffusion method as described in the manual of Clinical and Laboratory Standards Institute recommendations. The results were checked after $24 \mathrm{~h}$ incubation at $37 \mathrm{C}$ as sensitivity, intermediate sensitivity and resistant according to zone diameter around each antibiotic disk. Oxacillin disc resistance results were used to confirm MRSA strains.

Minimum inhibitory concentration (MIC) is the minimum concentration of an antimicrobial agent that could inhibit the visible growth of microorganisms after overnight incubation. MICs were determined on the broth dilution method. It included the culturing of similar doses of bacteria in wells of liquid media containing progressively lower concentrations of the antimicrobial agent. MIC was determined based on the growth pattern of bacteria. One gram of vancomycin was added in $200 \mathrm{~mL}$ water to make stock. It means $1 \mu \mathrm{L}$ of water contain $5 \mu \mathrm{g}$ vancomycin. $2 \mu \mathrm{L}$ stock was added in $10 \mathrm{~mL}$ of broth media to form $1 \mu \mathrm{g}$ vancomycin concentration per $\mathrm{mL}$ of media. Same like $4 \mu \mathrm{L}, 8 \mu \mathrm{L}$, $16 \mu \mathrm{L}$ and $32 \mu \mathrm{L}$ antibiotic stock were added in $10 \mathrm{~mL}$ broth media to form $2 \mu \mathrm{g}, 4 \mu \mathrm{g}, 8 \mu \mathrm{g}$ and $16 \mu \mathrm{g}$ vancomycin concentrations per $\mathrm{mL}$ of media. SPSS-26 was used for Data analysis. Cross tabulation was done and frequency was taken.

\section{RESULTS}

A total of 500 samples was collected from PIMS Hospital, Islamabad. Out of which 50 samples were from the blood ( 25 from female, 25 from male), 300 samples were from wound/pus in which 100 from pimples $(60 \mathrm{~F}, 40 \mathrm{M}), 100$ samples from accidental cuts (80M, 20F), 100 samples from operative cuts (73F, $27 \mathrm{M}), 50$ samples were from urine $(25 \mathrm{~F}, 25 \mathrm{M})$ and 100 samples were from a nasal fluid $(50 \mathrm{~F}, 50 \mathrm{M})$. To measure incidence, there was an immense need to collect a reasonable amount of samples, that's why we collected 500 samples. The samples were collected according to standard procedures and preceded the same day of collection. Table-I shows the number of samples and their origin.

MIC is the smallest concentration of an antibiotic which prevent visible growth of a bacterium. Vancomycin MIC was checked against $S$. aureus. The results were compared according to CLSI (MICs $>2 \mu \mathrm{g} / \mathrm{ml}$ should be reported as resistant $)^{10}$. According to results, only one out 97 samples was resistance. Table-IV showing the vancomycin resistance.

Blood samples inoculated in blood culturing tubes were placed in ABCS machine. This machine indicates the presence of staphylococcus aureus bacteria in samples. Nine samples were indicated as positive; those positive samples were cultured on $\mathrm{N}$-agar and again purified on $\mathrm{N}$-agar after colony morphology 
conformation. Wound/pus samples were cultured in broth to get bacterial colonies. Bacterial colonies were inoculated on $\mathrm{N}$-agar from the broth ${ }^{5-6}$, type of bacte-
S. aureus presence was confirmed through gram staining, all the $S$. aureus were positive gram staining. Results were reconfirmed through catalase test as all

Table-I: Prevalence of staphylococcus aureus.

\begin{tabular}{l|c|c|c|c|c|c|c|c|c}
$\begin{array}{l}\text { Origin of } \\
\text { Samples }\end{array}$ & $\begin{array}{c}\text { Total } \\
\text { No. of } \\
\text { Samples }\end{array}$ & $\begin{array}{c}\text { No. of } \\
\text { Samples } \\
\text { from } \\
\text { Female }\end{array}$ & $\begin{array}{c}\text { No. of } \\
\text { Samples } \\
\text { from Male }\end{array}$ & $\begin{array}{c}\text { Total } \\
\text { Staphylococcus } \\
\text { Aureus Positive }\end{array}$ & $\begin{array}{c}\text { No. of } \\
\text { Positive } \\
\text { Samples in } \\
\text { Females }\end{array}$ & $\begin{array}{c}\text { No. of } \\
\text { Positive } \\
\text { Samples in } \\
\text { Males }\end{array}$ & $\begin{array}{c}\text { Prevalence } \\
\text { in Female }\end{array}$ & $\begin{array}{c}\text { Prevalence } \\
\text { in Male }\end{array}$ & $\begin{array}{c}\text { Overall } \\
\text { Prevalence }\end{array}$ \\
\hline Wound / Pus & 300 & 143 & 157 & 63 & 21 & 42 & $14.68 \%$ & $26.7 \%$ & $21 \%$ \\
\hline Nasal Fluid & 100 & 50 & 50 & 17 & 8 & 9 & $16 \%$ & $18 \%$ & $17 \%$ \\
\hline Blood & 50 & 25 & 25 & 9 & 5 & 4 & $20 \%$ & $16 \%$ & $18 \%$ \\
\hline Urine & 50 & 25 & 25 & 8 & 3 & 5 & $12 \%$ & $20 \%$ & $16 \%$
\end{tabular}

rial colonies were grown on $\mathrm{N}$-agar. $\mathrm{S}$. aureus colony was purified on $\mathrm{N}$-agar after colony morphology character confirmation. Urine samples were inoculated on CLAD media and about 2-3 type of bacterial colonies were grown ${ }^{8}$, samples from urine were positive. S. aureus colony was purified on $\mathrm{N}$-agar. Nasal fluid samples were inoculated in broth and then on $\mathrm{N}-\operatorname{agar}^{7-8}$, type of bacterial colonies were found. Seventeen samples were $S$. aureus positive. S. aureus was purified on $\mathrm{N}$-agar. the $S$. aureus bacteria gave positive results for catalase. $S$. aureus colonies were grown at DNase media for further confirmation. All the $S$. aureus bacteria gave positive results for DNase test.

Total 500 samples were divided into four study groups designated as group 1, group 2, group 3 and group 4, based on samples from wound/pus, samples from the nasal cavity, samples from blood and samples from urine respectively.

Table-II: Percentage of resistance and susceptibility against the antibiotic disc.

\begin{tabular}{l|c|c|c}
\hline Antibiotics & Resistance & Intermediate & Susceptible \\
\hline Penicillin & $97 / 97(100 \%)$ & - & - \\
\hline Ciprofloxin & $91 / 97(94 \%)$ & - & $6 / 97(6 \%)$ \\
\hline Kanamycin & $91 / 97(94 \%)$ & $6 / 97(6 \%)$ & - \\
\hline Tetracyclin & $56 / 97(58 \%)$ & $6 / 97(6 \%)$ & $35 / 97(36 \%)$ \\
\hline Doxycycline & $39 / 97(40 \%)$ & $9 / 97(9 \%)$ & $49 / 97(51 \%)$ \\
\hline Erythromycin & $74 / 97(76 \%)$ & $20 / 97(21 \%)$ & $3 / 97(3 \%)$ \\
\hline Cefoxin & $36 / 97(37 \%)$ & $13 / 97(13 \%)$ & $48 / 97(50 \%)$ \\
\hline Clindamycin & $42 / 97(43 \%)$ & $6 / 97(6 \%)$ & $49 / 97(51 \%)$ \\
\hline Sulfamethoxazole & $46 / 97(47 \%)$ & $5 / 97(5 \%)$ & $46 / 97(47 \%)$ \\
\hline Oxazolidinone & $53 / 97(55 \%)$ & $17 / 97(17 \%)$ & $27 / 97(28 \%)$ \\
\hline (Antibtic & & \\
\hline
\end{tabular}

(Antibiotic Disc Dose (ug): (Penicillin 10, Ciprofloxin 5, Kanamycin 30, Tetracyclin 30, Doxycyclin 30, Erythromycin15, Cefoxin 30 Clindamycin 10, sulfamethoxazole 25, Oxazolidinone 30).

Table-III: MRSA and MSSA in islamabad.

\begin{tabular}{|c|c|c|c|c|c|c|c|c|c|}
\hline \multirow{2}{*}{$\begin{array}{l}\text { Sample } \\
\text { Origin }\end{array}$} & \multirow{2}{*}{$\begin{array}{l}\text { S. aureus } \\
\text { (positive) }\end{array}$} & \multicolumn{2}{|c|}{ S. aureus (positive) } & \multicolumn{2}{|c|}{ MRSA } & \multicolumn{2}{|c|}{ MSSA } & \multirow{2}{*}{$\begin{array}{l}\text { Overall } \\
\text { MRSA }\end{array}$} & \multirow{2}{*}{$\begin{array}{c}\text { Overall } \\
\text { MSSA }\end{array}$} \\
\hline & & Males & Females & Males & Females & Males & Female & & \\
\hline Wound & 63 & 42 & 21 & $40.47 \%$ & $47.62 \%$ & $59.52 \%$ & $52.38 \%$ & - & - \\
\hline Nasal fluid & 17 & 9 & 8 & $55.55 \%$ & $62.5 \%$ & $44.44 \%$ & $37.5 \%$ & - & - \\
\hline Blood & 9 & 4 & 5 & $75 \%$ & $60 \%$ & $25 \%$ & $40 \%$ & - & - \\
\hline Urine & 8 & 5 & 3 & $40 \%$ & $33.33 \%$ & $60 \%$ & $66.66 \%$ & - & - \\
\hline Total & 97 & 60 & 37 & $45 \%$ & $51.35 \%$ & $55 \%$ & $48.86 \%$ & $48.2 \%$ & $52 \%$ \\
\hline
\end{tabular}

(MRSA, Methicillin resistant staph aureus, MSSA, Methicillin susceptible staph aureus)

Table-IV: Vancomycin resistance in S. aureus.

\begin{tabular}{l|c|c|c}
\hline Antibiotic & Resistant & Intermediate & Susceptible \\
\hline Vancomycin & $1 / 97(1.03 \%)$ & 0 & $96 / 97(98.96 \%)$ \\
\hline
\end{tabular}

$48.2 \%$ samples were MRSA as they were resistant against oxacillin, and $52 \%$ samples were MSSA as they were susceptible to oxacillin. All the results were designed according to CLSI guidelines. Table-III shows the total MRSA and MSSA samples and their origin.
Presence of Staphylococcus aureus was checked and confirmed through different biochemical tests. All the S. aureus were grown on Mueller Hinton Agar to check their antibiotic disc resistance pattern. Table-I shows percentage of resistance and susceptibility 
against the antibiotic disc, figure shows Antibiotic disc analysis. sults showed that $36 \%$ of samples were susceptible, $6 \%$ intermediate and 58\% resistant. Doxycycline is mostly

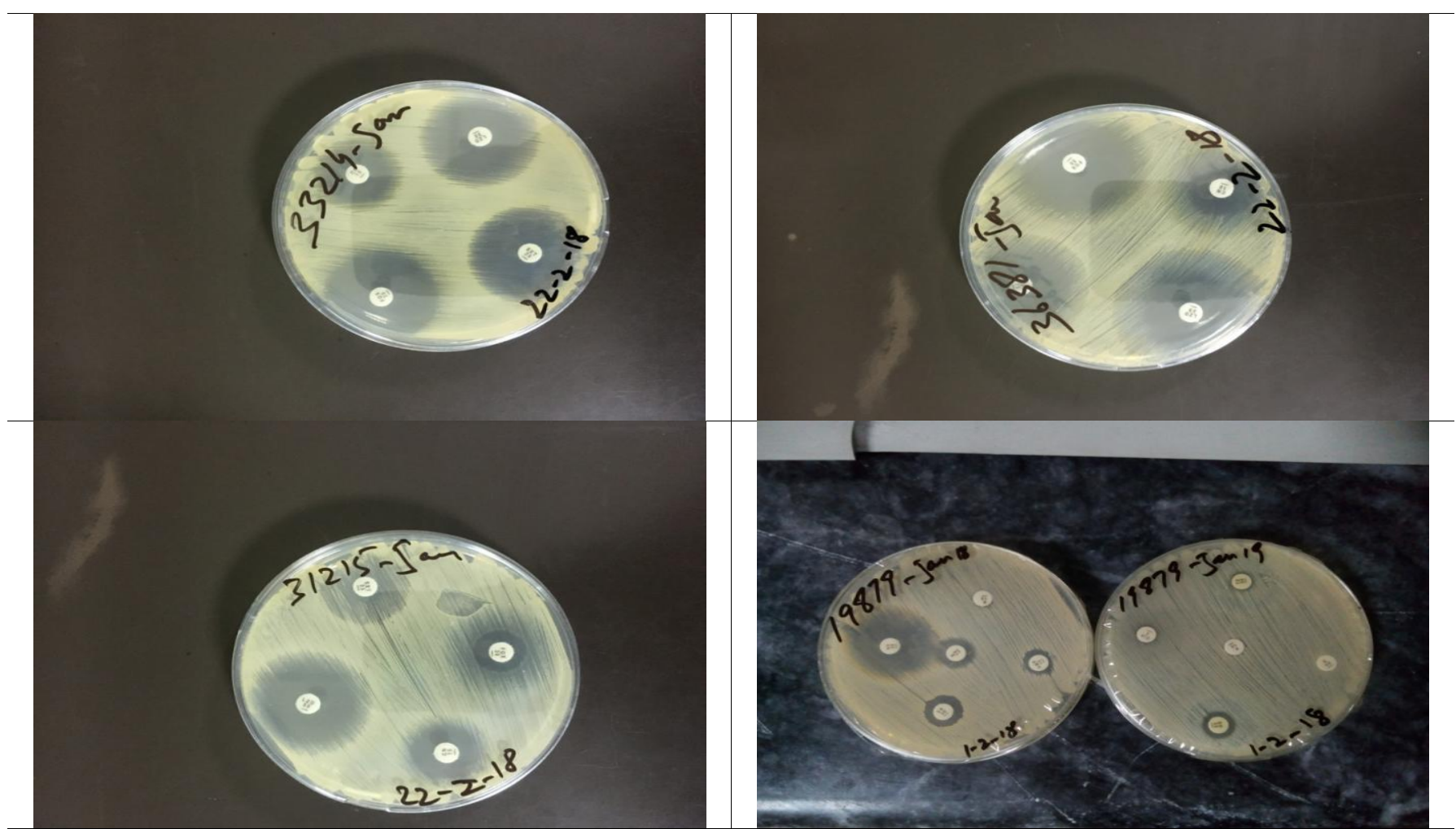

Figure: Antibiotic disc analysis.

\section{DISCUSSION}

S. aureus is a chief source of bacteraemia in hospitals and is the most common cause of necrotizing pneumonia, skin, and soft-tissue infections in the community ${ }^{11,12}$. In our study, $48.2 \%$ of samples were MRSA and 52\% samples were MSSA In 2016, a study in Peshawar reported a $36.1 \%$ frequency of MRSA ${ }^{13}$. Furthermore, of $47.42 \%$ MRSA, major $67.5 \%$ of MRSA was isolated from blood followed by $59 \%$ from the nasal fluid. About $36.6 \%$ (least) of MRSA was isolated from the urine, $51.35 \%$ MRSA isolates were from females (45\% from males) $)^{14}$.

Penicillin was the first-ever antibiotic which was used against any kind of bacteria. It is still in use, although many bacteria are resistance against it. 100\% samples of $S$. aureus were resistance against penicillin. Ciprofloxin is used against various bacteria causing skin infections. $6 \%$ S. aureus was susceptible while $94 \%$ was resistance against ciprofloxacin, $75.8 \%$ resistance was reported in 2011 study in Lahore ${ }^{15}$. Results against kanamycin showed that $6 \%$ of samples were intermediate and $94 \%$ were resistant. Tetracycline is also used as an antibiotic against infectious bacteria. Its disc re- used against the bacteria, which cause acne and skin infections. Fifty one percent of samples were susceptible, 9\% intermediate and 40\% resistant against doxycycline. Twenty one percent samples were intermediate, 3\% susceptible and 76\% resistant against Erythromycin. Cefoxin results show that $36 \%$ of samples were resistant, $13 \%$ intermediate and 50\% susceptible. $43 \%$ isolates were resistant, $6 \%$ intermediate and $51 \%$ susceptible against Clindamycin, sulfamethoxazole results show that $47 \%$ samples were resistant, $5 \%$ intermediate and $47 \%$ susceptible, while $55 \%$ samples were resistant, $17 \%$ intermediate and $28 \%$ susceptible against oxazolidinone. In other studies, the same procedural disc analyses have been done to identify the susceptibility and resistant pattern of $S$. aureus by using various types of antibiotics available in the market such Penicillin, Ampicillin, Amoxicillin, Streptomycin, Erythromycin, Lincomycin, Tetracycline, Neomycin; Amoxicillin, Clindamycin, SXT/trimethoprim / sulfamethoxazole, Cefoperazone, and Oxacillin ${ }^{16-19}$.

This study shows increased vancomycin resistance among MRSA strains in Rawalpindi/Islamabad area. Vancomycin MIC when checked against S. aureus 
in 97 samples one was resistant as the results were compared according to CLSI. In previous studies conducted in different areas of Pakistan ${ }^{15}$, no resistant VRSA strain was detected ${ }^{20}$. But latest studies have reported VRSA in Karachi and Peshawar ${ }^{21-23}$.

Although, our sample size is less as compared to the entire population; however, at least it covers the periphery of PIMS hospital and it could be evaluated that MRSA and MSSA are prevalent in the PIMS hospital environment. Hereby, it is recommended that there should be regular periodic reviews of hospitalacquired infections including antimicrobial sensitivity examinations and it would be quite helpful in drawing antibiotic policy for infection control and alleviating the prevalence of multidrug-resistant MRSA and MSSA.

\section{RECOMMENDATION}

Prescribing antibiotics other than glycopeptides for MRSA infections will lessen the probabilities of occurrence of VRSA. Good hospital infection control measures are most effective against these infections.

\section{CONCLUSION}

There is an increase in the frequency of MRSA among S. aureus isolates. Single VRSA strain was also isolated.

\section{CONFLICT OF INTEREST}

This study has no conflict of interest to be declared by any author.

\section{REFERENCES}

1. Vidhani S, Mehndiratta P. Study of methicillin resistant $S$. aureus (MRSA) isolates from high risk patients. 2001; 19(2): 13-16.

2. Alam SMS, Kalam MA, Munna MS, Munshi SK, Noor RJAPJoTD. Isolation of pathogenic microorganisms from burn patients admitted in Dhaka Medical College and Hospital and demonstration of their drug-resistance traits 2014; 4(5): 402-07.

3. Salas M, Wernecki M, Fernández L, Iglesias B, Gutiérrez D, Álvarez A, et al. Characterization of Clinical MRSA Isolates from Northern Spain and Assessment of Their Susceptibility to PhageDerived Antimicrobials. 2020; 9(8): 447.

4. Plata K, Rosato AE, Wegrzyn GJABP. Staphylococcus aureus as an infectious agent: overview of biochemistry and molecular genetics of its pathogenicity. 2009; 56(4): 1-5.

5. Chessa D, Ganau G, Mazzarello VJTJoliDC. An overview of staphylococcus epidermidis and staphylococcus aureus with a focus on developing countries. 2015; 9(06): 547-50.

6. Lima LM, da Silva BNM, Barbosa G, Barreiro EJ. $\beta$-lactam antibiotics: An overview from a medicinal chemistry perspective. 2020; 1(1): 112829-32.

7. Brown DF, Edwards DI, Hawkey PM, Morrison D, Ridgway GL, Towner KJ, et al. Guidelines for the laboratory diagnosis and susceptibility testing of methicillin-resistant staphylococcus aureus (MRSA) 2005; 56(6): 1000-18.
8. Hiramatsu K, Hanaki H, Ino T, Yabuta K, Oguri T, Tenover FJ. Methicillin-resistant staphylococcus aureus clinical strain with reduced vancomycin susceptibility. J Antimicrob Chemother 1997; 40(1): 135-36.

9. Hiramatsu K. Vancomycin-resistant staphylococcus aureus: a new model of antibiotic resistance. Lancet Infec Dis 2001; 1(3): 147-55.

10. Wilcox M, Al-Obeid S, Gales A, Kozlov R, Martínez-Orozco JA, Rossi F, et al. Reporting elevated vancomycin minimum inhibitory concentration in methicillin-resistant staphylococcus aureus: Consensus Inter Working Group 2019; 14(4): 345-52.

11. Vali L, Dashti AA, Mathew F, Udo EE. Characterization of heterogeneous MRSA and MSSA with reduced susceptibility to chlorhexidine in Kuwaiti hospitals 2017; 8(1): 1359-62.

12. Emre A, Seyman D, Turker M, Adiguzel Z, Gunay V, Tekeli A, et al. Cases with skin and soft tissue infections caused by community-acquired methicillin-resistant staphylococcus aureus/ toplum kokenli metisiline direncli staphylococcus aureus etkenli deri ve yumusak doku infeksiyonu olgulari. 2020; 33(2): 180-85.

13. Ullah A, Qasim M, Rahman H, Khan J, Haroon M, Muhammad $\mathrm{N}$, et al. High frequency of methicillin-resistant staphylococcus aureus in Peshawar Region of Pakistan. Springerplus 2016; 5(1): 600-05.

14. Sunagar R, Hegde NR, Archana GJ, Sinha AY, Nagamani K, Isloor SJJogar. Prevalence and genotype distribution of methicillin-resistant Staphylococcus aureus (MRSA) in India. J Glob Antimicrob Resist 2016; 7(1): 46-52.

15. Bukhari SZ, Ahmed S, Zia NJJoAMCA. Antimicrobial susceptibility pattern of Staphylococcus aureus on clinical isolates and efficacy of laboratory tests to diagnose MRSA: a multi-centre study. J Ayub Med Coll Abbottabad 2011; 23(1): 139-42.

16. Onwubiko NE, Sadiq NM. Antibiotic sensitivity pattern of staphylococcus aureus from clinical isolates in a tertiary health institution in Kano, Northwestern Nigeria. Pan African Medical J 2011; 8(1): 1-7.

17. Onile B, Odugbemi T, Nwofor C. Antibiotic susceptibility of bacterial agents of septicemia in Ilorin. Nig Med Pract 1985; 9(4): 16-18.

18. Obiazi H, Ekundayo A. Prevalence and antibiotic susceptibility pattern of staphylococcus aureus from clinical isolates grown at 37 and $44^{\circ} \mathrm{C}$ from Irrua, Nigeria. African J Microbiol Res 2007; 1(5): 57-60.

19. Naik D, Teclu A. A study on antimicrobial susceptibility pattern in clinical isolates of staphylococcus aureus in Eritrea. Pan African Med J 2009; 3(1): 1-5.

20. Kaleem F, Usman J, Sattar A, Amanat ST, Hassan A, Omair M, et al. Current status of vancomycin susceptibility against methicillin resistant staphylococcus aureus (MRSA) strains: A study at two tertiary care hospitals of Pakistan. African J Microbiol Res 2012; 6(33): 6243-46.

21. Siddiqui T, Muhammad IN, Khan MN, Naz S, Bashir L MRSA: Prevalence and susceptibility pattern in health care setups of Karachi. Professional Med J 2017; 30(Suppl-6): 2417-21.

22. Ahmad S, Ahmed S, Sabir MS, Khan H, Rehman M, Niaz ZJ. Frequency and comparison among antibiotic resistant staphylococcus aureus strains in selected hospitals of Peshawar, Pakistan. J Pak Med Assoc 2020; 70(7): 1199-202.

23. Jayaweera J, Karunarathne M, Kumbukgolla WW. The importance of timely introduction of vancomycin therapy against methicillin-resistant staphylococcus aureus (MRSA) bacteremia and severity of MRSA bacteremia at Teaching Hospital, Anuradhapura, Sri Lanka. Inter J One Health 2017; 3(1): 7-11. 